ИЗВЕСТИЯ АКАДЕМИИ НАУК ЭСТОНСКОИ ССР. ТОМ 25 ХИМИЯ * ГЕОЛОГИЯ. 1976, № 3

\title{
О ВОЗРАСТЕ МАКСИМАЛЬНОИ ЛИТОРИНОВОЙ ТРАНСГРЕССИИ В ЛЕНИНГРАДСКОЙ ОБЛАСТИ
}

Развитие Балтики во время атлантического климатического периода характеризуется сочетанием эвстатических и неотектонических процессов. В это время на фоне улучшения планетарных климатических условий происходило интенсивное таяние ледникового покрова, что повлекло за собой эвстатическое поднятие уровня Мирового океана. Произошли также значительные изменения в режиме неотектонического поднятия Балтийского щита и его обрамления. Уменьшение градиента поднятия земной коры и погружение некоторых частей Балтики обусловили метахронность максимальных береговых линий Литөринового моря. В районах с большим градиентом поднятия береговые образования трансгрессивных фаз Литоринового моря отчетливо отделены друг от друга. Например, в Онгерманланде (Средняя Швеция) береговая линия ранней литориновой фазы $\left(L_{\mathrm{I}}\right)$ прослеживается на абсолютной отметке $90 \mathrm{M}$, а уровни более поздних фаз ( $\left.L_{\text {II и }} L_{\text {III }}\right)$ - на абсолютных отметках 85 и 65 м соответственно (Nilsson, 1970).

В южной части Балтики формирование береговых линий определяло в основном эвстатическое изменение уровня воды, и выделение отдельных трансгрессивных фаз представляет здесь сложную задачу.

Обычно литориновые береговые образования фаз $L_{\mathrm{II}}$ и $L_{\mathrm{IV}}$ в названной части бассейна слабо выражены и трудно отличимы. Кроме указанных, существовала еще одна фаза Литоринового моря в суббореальном климатическом периоде. Абсолютная отметка береговых образований ее в Литве и Сконе составляет около 5 м (Гуделис, 1969; Berglund, 1971). В зависимости от конкретных эвстатических и неотектонических условий суббореальная береговая линия Литоринового моря может иметь или трансгрессивный или регрессивный характер. Как показывают наши исследования на побережье Рижского залива в разрезе Гипка, возраст суббореальной литориновой трансгрессии около $3800-4000$ лет (Гринбергс и др., 1974).

Береговая зона Литоринового моря в Эстонии занимает переходную территорию, где скорость неотектонического поднятия была относительно небольшой и большинство установленных береговых образований Литоринового моря формировалось под влиянием поздней (атлантической) литориновой трансгрессии (фазы $L_{\text {II }}$ ). Более ранние литориновые береговые образования (фаза $L_{\mathrm{I}}$ ) установлены только на п-ове Кыпу в северозападной части Әстонии, выше 20-метровой изобазы (Кессел, Раукас, 1967). На всей остальной территории наивысшим уровнем являются бере-

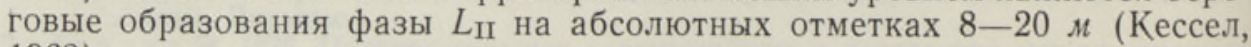
1963). 
Согласно палинологическим данным, ранняя литориновая трансгрессия произошла во время АТ 1 * фазы развития лесов и поздняя трансгрессия - во время АТ 2 фазы (Кессел, Раукас, 1967). Их радиоуглеродные возрасты соответственно 6800-7000 и 5800-6000 лет (Кессел, Пуннинг, 1969). В северо-восточной и юго-западной частях Әстонии однозначно выделить и датировать отдельные трансгрессии Литоринового моря пока невозможно. Неясно, образовались береговые образования здесь в связи с максимальным распространением Литоринового моря во время фазы $L_{\text {II }}$ или позже. В юго-западной части Әстонии и северо-западной части Латвии в разрезах Раннаметса и Светупе литориновые береговые образования обнаружены почти на одинаковых абсолютных высотах (выше 6 м). Как известно, в разрезе Светупе накопление озерных отложений прекратилось в конце атлантического периода около 4500 лет назад (Гринбергс и др., 1974).

Большие возможности для выяснения возраста максимального литоринового уровня дают разрезы литориновых отложений в Ленинградской области, где соответствующая береговая линия залегает ниже абсолютной высоты 12 м. Эти довольно малочисленные разрезы - Систа-Палкино, Сосновый Бор, Чёрная речка (Молодежное) и др. - исследовались

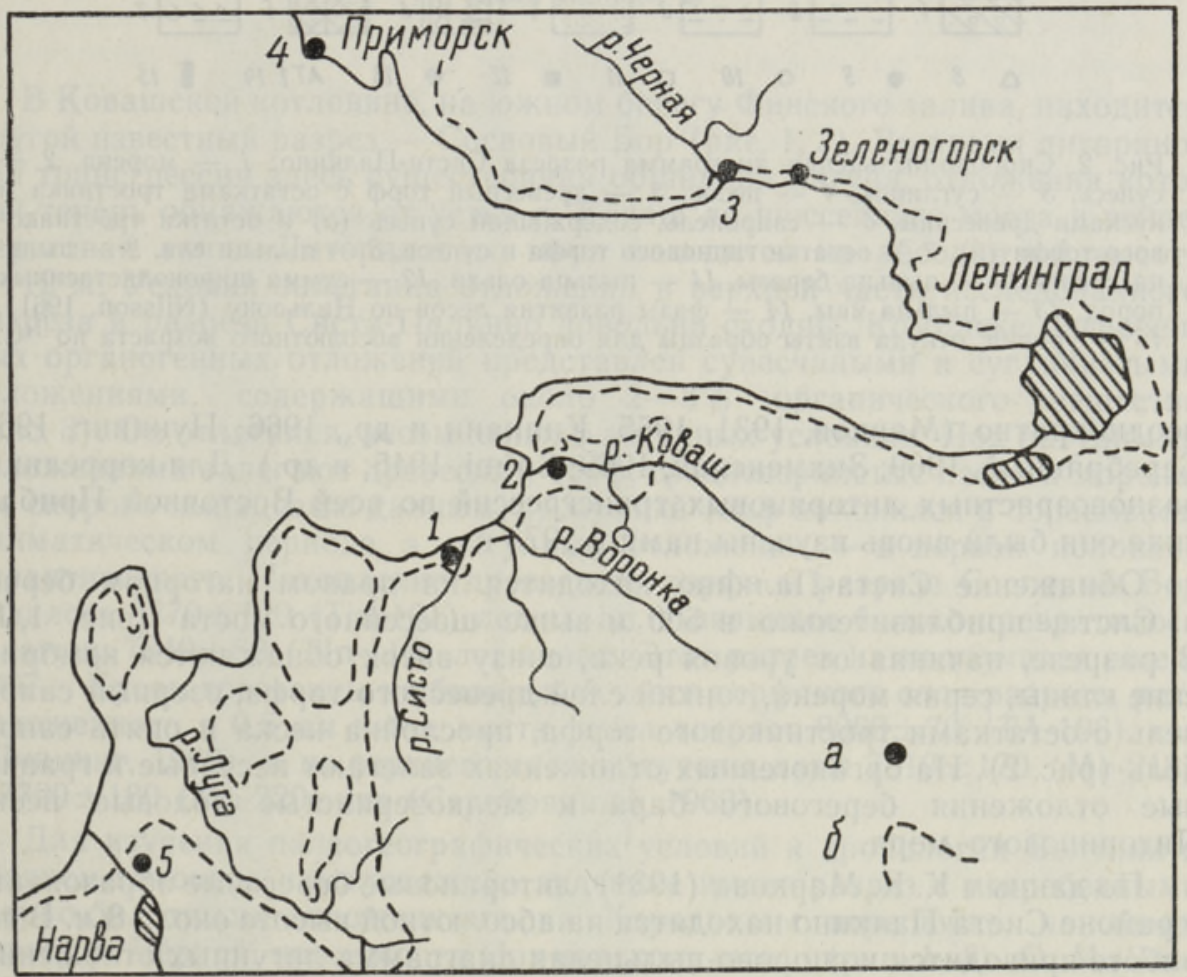

Рис. 1. Местонахождения погребенных органогенных отложений под литориновыми береговыми образованиями в Ленинградской области: $a$ - места отбора образцов для спорово-пыльцевого анализа и радиоуглеродных датировок: 1 - Систа-Палкино, 2 - Сосновый Бор, 3 - Чёрная речка, 4 - Приморск, 5 - Тырвала; $6-$ литориновая береговая линия $\left(L_{\mathrm{II}}\right)$.

* Фазы развития лесов даны по схеме П. Томсона (Thomson, 1929), индексы фаз - по Т. Нильссону (Nilsson, 1961). 


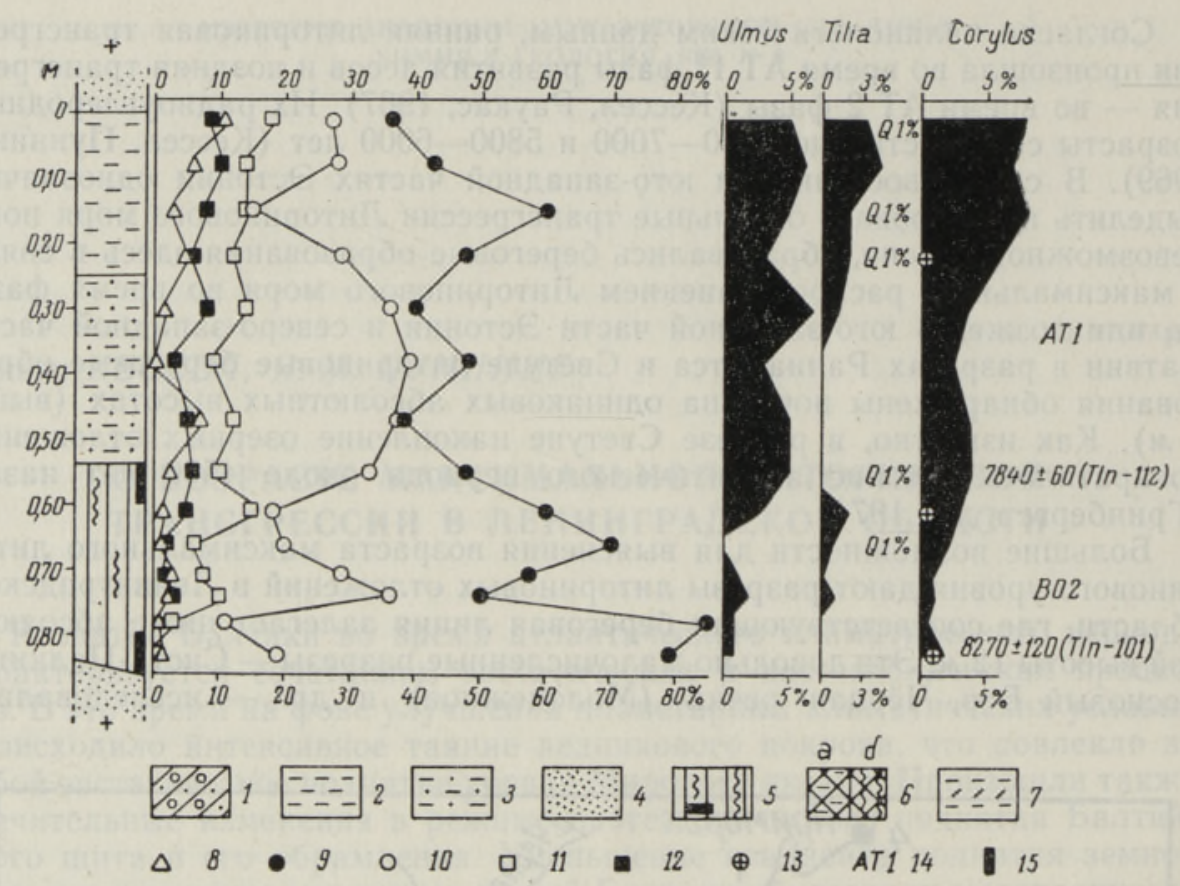

Рис. 2. Спорово-пыльцевая диаграмма разреза Систа-Палкино: 1 - морена, 2 супесь, 3 - суглинок, 4 - песок, 5 - древесный торф с остатками тростника и кусками древесины, 6 - сапропель, содержащий супесь $(a)$ и остатки тростникового торфа (б), 7 - остатки гипнового торфа в супеси, 8 - пыльца ели, 9 - пыльца сосны, 10 - пыльца березы, 11 - пыльца ольхи, 12 - сумма широколиственных пород, 13 - пыльца ивы, 14 - фазы развития лесов по Нильсону (Nilsson, 1961), 15 - уровни, откуда взяты образцы для определения абсолютного возраста по ${ }^{14} \mathrm{C}$.

неоднократно (Марков, 1931, 1955; Кипиани и др., 1966; Пуннинг, 1969; Серебрянный, 1969; Знаменская, 1969; Salmi, 1945; и др.). Для корреляции разновозрастных литориновых трансгрессий во всей Восточной Прибалтике они были вновь изучены нами в 1973 г.

Обнажение Систа-Палкино находится на правом нагорном берегу р. Систа, приблизительно в 500 м выше шоссейного моста (рис. 1,1). В разрезе, начиная от уровня реки, снизу вверх обнажаются кембрийские глины, серая морена, тонкий слой древесного торфа, озерный сапропель с остатками тростникового торфа, прослойка песка и опять сапропель (рис. 2). На органогенных отложениях залегают песчаные и гравийные отложения берегового бара и мелкозернистые эоловые пески Литоринового моря.

По данным К. К. Маркова (1931), литориновые береговые образования в районе Систа-Палкино находятся на абсолютной высоте около 8 м. В его работе приводится и спорово-пыльцевая диаграмма лагунных отложений. Эта диаграмма в основных чертах похожа на составленную нами диаграмму. Для верхней части озерных отложений характерно относительно высокое содержание пыльцы широколиственных пород, в основном пыльцы вяза и липы. Судя по диаграмме, можно полагать, что накопление озерных отложений происходило во время атлантического климатического оптимума и прекратилось после него. Датирование отложений по ${ }^{14} \mathrm{C}$ показало, что комплекс погребенных органогенных отложений накапливался от 6000 до 7980 лет назад (рис. 2). 


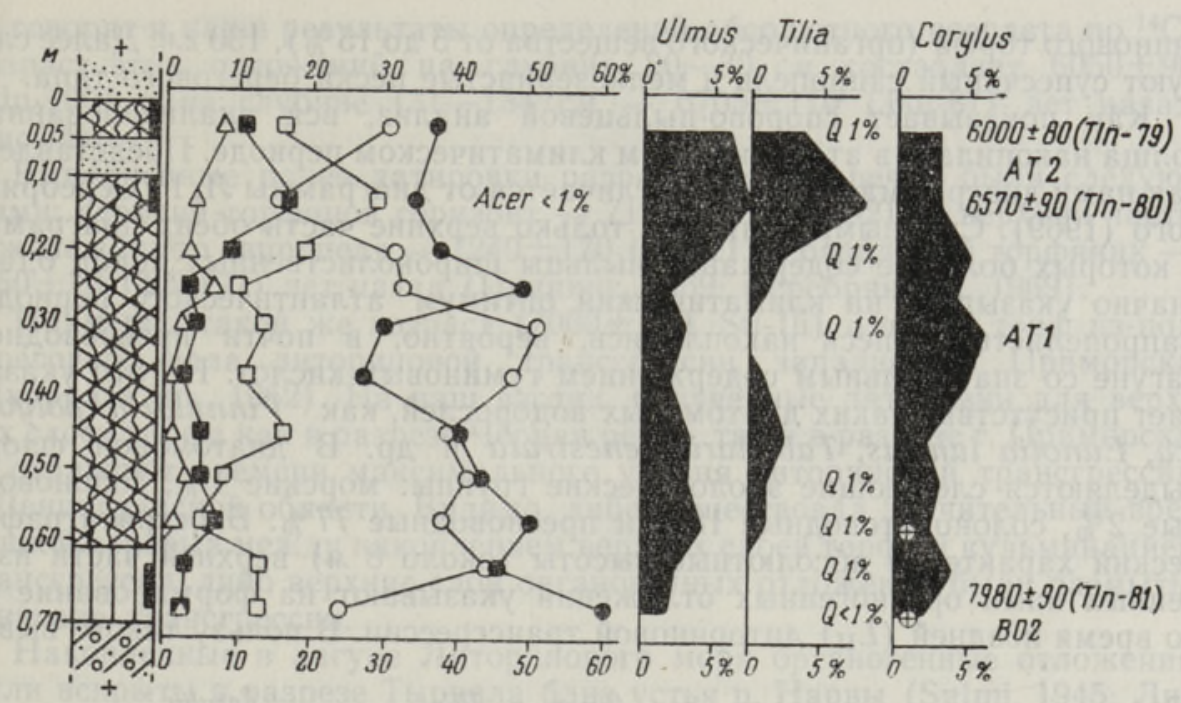

Рис. 3. Спорово-пыльцевая диаграмма разреза Сосновый Бор. Условные обозначения см. рис. 2.

В Ковашской котловине, на южном берегу Финского залива, находится другой известный разрез - Сосновый Бор (рис. 1,2). Во время литориновой трансгрессии здесь существовала обширная лагуна, отложения которой теперь обнажаются от устья р. Коваш до шоссейного моста и выше. Береговая линия Литоринового моря находится на абсолютной высоте 9-12 м. Условия залегания отложений в верхней части исследованного разреза и разреза Систа-Палкино довольно сходны. Комплекс погребенных органогенных отложений представлен супесчаными и суглинистыми отложениями, содержащими около $2-8 \%$ органического вещества (рис. 3). Он отлагался, несомненно, в лагунных условиях. Под лагунными отложениями залегают древесный торф, среднезернистые пески и морена. По спорово-пыльцевым данным, древесный торф накопился в бореальном климатическом периоде, а лагунные отложения - в первой половине атлантического. Накопление древесного торфа в разрезе Сосновый Бор началось $8270 \pm 120$ (Tln-101) лет назад, и низинное болото превратилось в лагуну $7840 \pm 60(T \ln -112)$ лет назад. Этот разрез нами изучался еще в 1967 г. Кусок древесины из базальной части торфяного слоя разреза, расположенного в $0,5 \kappa м$ ниже моста, имел возраст $8060 \pm 70$ (ТА-196) лет (Пуннинг, 1969), а из верхнего слоя получены даты 7810 170 (Мо-218) и $7720 \pm 180($ Мо-220) лет (Серебрянный, 1969).

Для изучения палеогеографических условий и хронологии Балтики в среднем голоцене немаловажное значение имеет разрез с погребенными озерно-болотными отложениями на Карельском перешейке, на левом берегу р. Чёрной, ниже моста Приморского шоссе (рис. 1, 3). О. М. Знаменская (1969) и Л. Р. Серебрянный (1969) выделяют в этом разрезе три погребенные террасовые поверхности (послеиольдиевую, послеанциловую и речную пойменную). Последняя терраса погребена под отложения дельты р. Чёрной и береговые валы Литоринового моря.

В изученной нами расчистке в южной части обнажения Чёрная речка в озерно-болотной толще выявляются следующие горизонты (сверху вниз, рис. 4): суглинок пылеватый с растительными остатками мощностью 40 см; древесный торф, бурый, 3 см; супесь сапропелистая с прослойками 
гипнового торфа (органического вещества от 5 до 15\%), 130 см. Далее следуют супесчаный сапропель и мелкозернистые пески берегового типа.

Как показывает спорово-пыльцевой анализ, вся анализированная толща накопилась в атлантическом климатическом периоде. Представленная нами диаграмма несколько отличается от диаграммы Л. Р. Серебрянного (1969). Сходными являются только верхние части обеих диаграмм, в которых большое содержание пыльцы широколиственных пород однозначно указывает на климатический оптимум атлантического периода. Сапропелистые супеси накоплялись, вероятно, в почти пресноводной лагуне со значительным содержанием гуминовых кислот. На это указывает присутствие таких диатомовых водорослей, как Pinnularia polyonca, Eunotia lunaris, Tabellaria fenestrata и др. В диатомовой флоре выделяются следующие экологические группы: морские 1\%, солоноводные $2 \%$, солоноватоводные $18 \%$ и пресноводные $77 \%$. Биостратиграфический характер и абсолютные высоты (около $8 \mu$ ) верхней части изученных нами органогенных отложений указывают на формирование ее во время поздней $\left(L_{\Pi}\right)$ литориновой трансгрессии. В пользу такого выво-

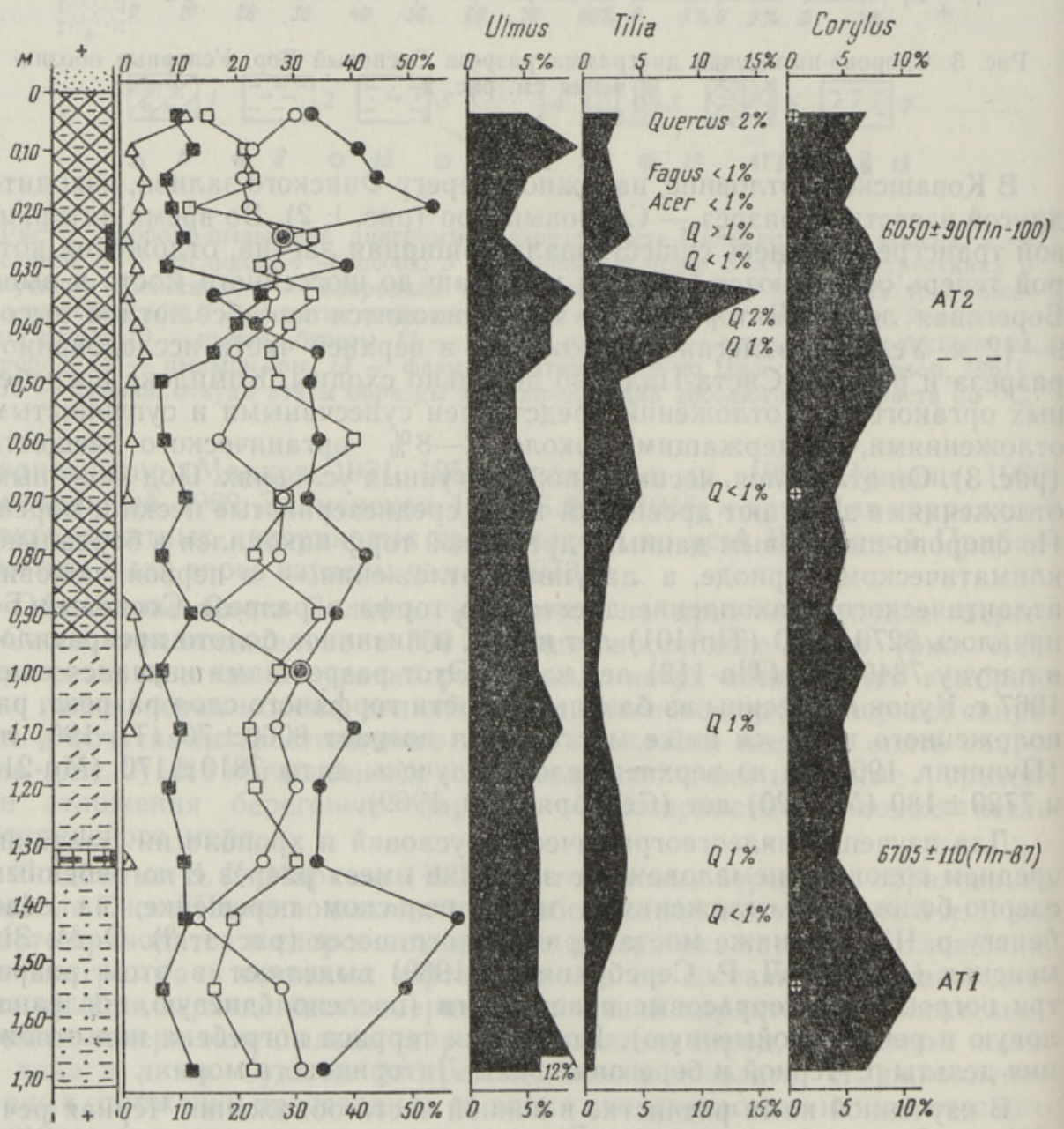

Рис. 4. Спорово-пыльцевая диаграмма разреза Чёрная речка. Условные обозначения см. рис. 2. 
да говорят и наши результаты определений абсолютного возраста по ${ }^{14} \mathrm{C}$. Возраст этих отложений на глубине 20-30 см составляет $6050 \pm 90$ $(\mathrm{T} \ln -100)$ и на глубине $131-134$ см $-6705 \pm 110(\mathrm{~T} \ln -87)$ лет назад (рис. 4).

Выполненные ранее датировки разреза Чёрная речка были следую-

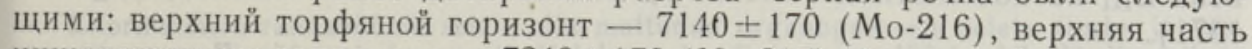
нижележащего сапропеля - $7240 \pm 170$ (Мо-217), базальный торфяник $7350 \pm 70$ (ТА-197) лет назад (Пуннинг, 1969; Серебрянный, 1969).

Примерно такой же возраст $(7000 \pm 180$, Su-16) имеет и торф нз-под берегового вала литориновой трансгрессии западнее г. Приморска (Нууррӓ и др., 1962). На наш взгляд, полученные датировки для верхних слоев торфа как в разрезе Чёрная речка, так и в разрезе г. Приморска не отражают времени максимального уровня литориновой трансгрессии в Ленинградской области. Видимо, либо существовал значительный временной перерыв между накоплением верхних слоев торфа и кульминацией трансгрессии, либо верхние слои органогенных отложений были размыты в начале трансгрессии.

Накопленные в лагуне Литоринового моря органогенные отложения были вскрыты в разрезе Тырвала близ устья р. Нарвы (Salmi, 1945; Лисицына, 1959; Кессел, 1963; Кессел, Раукас, 1967) (рис. 1, 5). По данным М. Сальми, сфагновый торф и диатомовые отложения в разрезе Тырвала накоплялись со второй половины бореального до середины атлантического климатического периода. Возраст базального торфяника данного разреза $7370 \pm 120$ (Ле-12) (Старик, Арсланов, 1961) показывает, что возникновение лагуны совпадает по времени с кульминацией ранней литориновой трансгрессии. Как известно, в Эстонии это событие датировано возрастом 6800-7000 лет (Кессел, Пуннинг, 1969). Накопление лагунного диатомита происходило с первой половины атлантического периода до климатического оптимума, который характеризовался максимальным распространением пыльцы широколиственных пород $(21 \%)$ и высоким содержанием пыльцы лещины в верхней части спорово-пыльцевой диаграммы (Кессел, 1963). Накопление диатомита прекратилось под влиянием поздней литориновой трансгрессии, когда соответствующая береговая линия достигла в Нарвском заливе абсолютной высоты $10 \mathrm{~m}$. Тонкие прослойки диатомитового песка свидетельствуют об эпизодических поднятиях уровня
моря.

Итак, с учетом всей совокупности данных, временной интервал между регрессией Анцилового озера и кульминацией Литоринового моря в восточной части Финского залива составляет около 1000 лет. Радиоуглеродные данные показывают, что накопление торфа в разрезе Сосновый Бор началось около 8300 лет и в разрезе Тырвала прекратилось только 7400 лет назад. Кульминация трансгрессии Литоринового моря в изученном районе происходила непосредственно после климатического оптимума атлантического периода около 6000 лет назад. Эта трансгрессия формировала разные береговые образования на абсолютных высотах от 8 до $13 \mathrm{~m}$.

Полученные данные подтверждают вывод К. К. Маркова (1955) об одной литориновой трансгрессии в Ленинградской области. По нашему мнению, из-за небольшой скорости поднятия земной коры в неотектонически относительно стабильных районах разновозрастные уровни Литоринового моря сливаются. Видимо, на этом общем фоне непрерывного повышения уровня моря можно выделить отдельные этапы стабилизации. В условиях стабилизации образовались прибрежные озера (Систа-Палкино) и лагуны (Тырвала, Сосновый Бор, Чёрная речка). После стабилизации продолжалось повышение уровня моря и отложения в этих водоемах перекрывались морскими и береговыми отложениями. 
Эту литориновую трансгрессию возрастом около 6000 лет назад в Ленинградской области можно сопоставить с трансгрессией в северовосточной и юго-западной Эстонии (Кессел, Пуннинг, 1969). Аналогичный возраст (около 6000 лет) имеет трансгрессивный литориновый уровень $L_{\text {III }}$ на абсолютной отметке 7,5 м в Восточном Блекинге (Berglund, 1971).

Таким образом, можно заключить, что трансгрессия Литоринового моря кульминировала в Восточном Блекинге, юго-западной и северовосточной Эстонии и Ленинградской области одновременно около 6000 лет назад.

Авторы выражают глубокую благодарность Т. Какуму и Р. Раямяэ за помощь в полевых и аналитических работах.

\section{Л И Т Е Р А Т Р Р}

Гринбергс Э. Ф., Кессел Х. Я., Пуннинг Я.-М. К., Раямяэ Р. А. 1975. Применение радиоуглеродного метода для изучения древнебалтийских трансгрессий в Латвии. М.

$Г$ удели с В. 1969. Древнеледниковые образования Балтийского моря на территории Советской Прибалтики и Ленинградской области. В сб.: Последний ледниковый покров на Северо-Западе Европейской части СCCP. K VIII конгрессу INQUA, Париж, 1969. М.

3 н а м е н ска я О. М. 1969. Описание маршрута научной экскурсии. В сб.: Проблемы современных движений земной коры. Третий Междунар. симпозиум. Ленинград, CCCP, 1968. M.

Кессел Х. Я. 1963. Возраст трансгрессий голоценовых бассейнов Балтики в Эстонии по палинологическим данным. Baltica, 1. Вильнюс.

Кессел Х. Я., Р аукас А. В. 1967. Прибрежные отложения Анцилового озера и Литоринового моря в Эстөнин. Таллин.

Кессел Х., Пуннин Г Я.-М. 1969. Об абсолютном возрасте. голоценовых трансгрессий Балтики на территории Эстонин. Изв. АН ЭССР, Хим. Геол., 18, № 2.

Кипи ани М. Г., Короткевич Л. С., Колбутов А. Д., Купцов И. А. 1966. Об одном из опорных разрезов поздне- и послеледниковых отложений северовостока Прибалтики. В кн.: Матерналы исследования по археологии СССР, № 126. М.-Л.

Л и с и цын а Г. Н. 1959. Вопросы палеогеографии позднеледникового времени на территории северо-запада Европейской части СССР. В сб.: Ледниковый период на территории Европейской части СССР и Сибири. М.

Марков К. 1931. Развитие рельефа северо-западной части Ленинградской области. Тр. геолого-разведочн. управления ВСНХ СССР, вып. 117.

М ар ков К. К. 1955. Очерки по географии четвертичного периода. М.

Пуннинг Я.-М. 1969. Применение радиоуглеродного метода для изучения истории покровного оледенения в верхнем плейстоцене и эволюции древнебалтийских водоемов в раннем и среднем голоцене на территории Прибалтики. Автореф. канд. дис. Таллин.

С ереб ря н ны й Л. Р. 1969. Палеогеография и радиохронология Восточной Прибалтики на рубеже раннего и среднего голоцена. В сб.: Голоцен. М.

С т ар и К И. Е., А р сл ан о В. А. 1961. Возраст по радиоуглероду некоторых образцов четвертичного периода. Докл. АН СССР, 138, № 1.

B e r g l u n d B. E. 1971. Littorina transgression in Blekinge, South Sweden. A preliminary survey. Geol. Föreningens i Stockholm Förhandlingar, 93.

H y у р рӓ E., H of f r e n V., I s o 1 a A. 1962. Geological survey of Finland radiocarbon measurements 1. Radiocarbon, 4.

$\mathrm{Nils}$ s on T. 1961. Ein neues Standardpollendiagramm aus Bjarsjöholmssjön in Schonen. Lunds Univ. Årsskr. N. F. (2), 56, № 18.

$\mathrm{Nilss}$ on E. 1970. On the Late-Quaternary history of Southern Sweden and the Baltic basin. Baltica. 4. Vilnius.

$\mathrm{S}$ a $1 \mathrm{~m} \mathrm{i} \mathrm{M.} \mathrm{1945.} \mathrm{Ein} \mathrm{von} \mathrm{Littorina-Transgression} \mathrm{überspültes} \mathrm{Torflager} \mathrm{in} \mathrm{NE-Estland}$ zwischen Narva und Narva-Jõesuu. Acta Geogr. 9, Nr. 4. Helsinki.

Th o m s o n P. W. 1929. Die regionale Entwicklungsgeschichte der Wälder Estlands. Acta Univ. Tart., A, XVII. 


\section{LITORIINAMERE MAKSIMAALSE TRANSGRESSIOONI VANUSEST LENINGRADI OBLASTIS}

Litoriinamere rannavööndi setete alla mattunud organogeensete setete (turba ja sapropeeli) vanuse määramiseks uuriti õietolmu- ja diatomeeanalüüsi abil ( $\mathrm{H}$. Kessel) ja radioaktiivse süsiniku meetodil (J.-M. Punning) neljast leiukohast võetud proove. Võrdluseks on kasutatud Tõrvala leiukoha proovide analüüsi tulemusi (joon. 1).

Litoriinamere rannamoodustised, mille absoluutne kōrgus Leningradi oblastis on 8$13 \mathrm{~m}$, on tekkinud seoses Litoriinamere hilisema transgressiooniga. Organogeensed setted pärinevad boreaalsest ja atlantilisest kliimaperioodist, metsade arenemise faasidest BO 2, AT 1 ja AT 2 (joon. 2-4). Nad mattusid Litoriinamere rannamoodustiste alla vahetult pärast atlantilist kliimaoptimumi, u. 6000 aastat tagasi. Sellele eelnes u. 1000 aasta pikkune kontinentaalne periood.

Leningradi oblasti, Kirde- ja Edela-Eesti (Кессел, Пуннинг, 1969) ning Ida-Blekinge (Berglund, 1971) leiukohtade materjalide ja dateeringute hea sobivus lubab arvata, et nimetatud rannikupiirkondades on Litoriinamere maksimaalsed transgressioonid ühevanused.

Helgi KESSEL, J.-M. PUNNING

\section{ON THE AGE OF MAXIMAL TRANSGRESSION OF THE LITTORINA SEA IN LENINGRAD DISTRICT}

In order to determine the age of the organogenic deposits (peat and sapropel) buried under the coastal sediments of the Littorina Sea, samples were taken from 4 different points for pollen and diatom analysis (H. Kessel) and for radiocarbon dating (J.-M. Punning). For comparison, analogical analysis results from Törvala were used.

Coastal forms of the Littorina Sea which occur at the absolute height of $8-13 \mathrm{~m}$ in Leningrad District have developed in connection with the later transgression of the Littorina. In the given area the corresponding buried organogenic deposits are due to Boreal and Atlantic climatic periods. Their age ranges from BO 2 until AT 2 forest phases (Figs. $2-4)$. The organic deposits were buried under the Littorina coastal sediments at the maximal height immediately after the Atlantic optimum (about 6000 years back) that was preceded by a continental period of about 1000 years.

Since the materials and datings from Leningrad District, North-East and South-West Estonia (Кессел, Пуннинг, 1969) and East Blekinge (Berglund, 1971) can be well compared, the maximal transgression of the Littorina Sea in the above-mentioned coastal zones may possibly be contemporaneous. 